\title{
The Effects of Risk and Hedonic Value on the Intention to Purchase on Group Buying Website: The Role of Trust, Price and Conformity Intention
}

\author{
Yu-Chen Chen", Rong-An Shang, Chun-Yu Shu, Chung-Kuang Lin \\ Department of Business Administration, Soochow University, Taiwan
}

Copyright (C) 2015 by authors, all rights reserved. Authors agree that this article remains permanently open access under the terms of the Creative Commons Attribution License 4.0 International License

\begin{abstract}
By assuming that group buying websites offer consumers an opportunity to gain consumption value from experiential products with potential risks, a theoretical model was proposed to explore the factors affecting buyers' purchase intentions. In this model, trust, price consciousness and conformity behavior were viewed as antecedents of risks. A study of 164 responses found that the purchase intention was induced primarily by hedonic value; while at the same time, perceived risks will decrease the subjects' purchase intention, and trust is the only one that can effectively reduce the risks. The results indicate that whether to purchase in group buying website or in brick-mortar stores is actually a trade-off between the perceptions of values gained and risks exposed; and trust plays a pivotal role in reducing risk, leading to stronger purchase intention. Finally, academic and managerial implications are offered.
\end{abstract}

Keywords Group Buying, Hedonic Value, Trust, Price, Conformity Behavior, Risk

\section{Background and Motivation}

In December 2010, a new model of group buying (group buying website or the website, hereafter) was introduced into Taiwan by GROUPON, allowing a lot of strangers to purchase a coupon for consuming products in brick and mortar stores (coupon, hereafter) at very low prices. In just a few months, this new type of channel became widely accepted by Internet consumers in Taiwan, attracting many companies rushed into this business. The competition in this market is hence becoming high, forcing some of them to stop their operations and leave this business a just a few years ${ }^{1}$.

1 http://news.m.pchome.com.tw/society/tvbs/20141224/index-1419399511 0098139002.html; accessed in 2014/12/25
To improve the situations of remaining players, it became critical to know why consumers choose to buy products in such website.

Edelman, Jaffe and Kominers [22] argued that group buying businesses may increase their competitive positions by offering diversified products with low prices. Products offered in the website are mainly experiential products like food, snack, dessert, clothes, etc., that are mainly offered by new startups. From consuming such products, one can gains a variety of new experiences, which is quite attractive for novelty-seeking consumers.

However, the results from consuming experiential products may be uncertain, since people can't be sure the quality of experiential products before the consumption. Press and medium were overwhelmed with reports of anecdotal evidence of inferior experiences ${ }^{2}$. Previous literature indicated that efforts to build trust might effectively reduce the perception of uncertainty, and enhance consumers' purchase intention [23]. The roles of perceived trust and risk have been highlighted in literature of e-commerce too $[26,46]$; it is claimed that a higher degree of trust will lead to a lower perception of risk. Yet, a large proportion of stores in the website are mainly unknown or unfamiliar new startup businesses [20]. Therefore, it may be difficult for people to trust in these stores.

This study speculated that, besides trust, the features of great amount of people buying a same product at a low level of price may be complemental mechanisms for decreasing risk, making purchasing in the website become a risk-controlled behavior. Price acts as the informational cue of product quality, and help people make informed decision [45]. Baron, Vandello and Brunsman [6] also proposed that conformity behavior help people make informed decision and accurate judgment to reduce uncertainty when faced

2 e.g., see http://www.inside.com.tw/2011/01/02/failed-meal-groupon, accessed in 2012/6/20; and

http://www.inside.com.tw/2011/02/14/groupon-hk-flower-failed, accessed in $2012 / 6 / 20$ 
with a lack of information.

This study will conduct an empirical research to explore the validity of the above assertions, hoping to offer an explanation why people would choose to buy in the website while negative anecdotal hearsays circulated widely. This study argued that, in addition to the efforts to build trust, the difference in the performance of raising the size of the group buying experiential and new products in relatively lower prices, may contribute partially to the difference of competitive advantage of the group buying companies. Accordingly, the objectives of this study are two folds:

1. Building a theoretical model, by interrelating the concepts of value, uncertainty, trust, risk, price and conformity behavior, to explain why people would be willing to buy products in the website while perceiving the uncertainty of decision outcomes;

2. Conducting an empirical research to examine the validity and explanatory power of this model.

\section{Theoretical Background and Hypotheses}

The roles of price, value, conformity behavior, and trust and risk in determining purchase intention have been examined by many researchers [e.g., see 12]. However, most of these studies examine only individuals' consumption behavior, rather than their decision makings within the context of a group of people. In a study of group auction behavior, Yen and Chang [53] described the formation of purchase intention as a process of a group of people collectively planned their behavior. They hence introduce the concept of collectivism to adapt and augment the theory of planned behavior (TPB) to explain the behaviors of these groups of people.

The TPB is a framework for understanding the effect of attitude, subjective norms, and perceived behavioral control on intention to engage in behavior of interest [1]. TPB asserts that one's behavioral intention is directly influenced by his/ her attitude, perceived behavioral control and subjective norms. TPB has been proven successful in predicting and explaining human behavior across various self-interested behavioral contexts [2]. It is widely used in different academic fields, including online shopping behavior [e.g., 29]. Yen and Chang [53] further proved that TPB can be used to explain individuals' behavior influenced by a group of strangers' dynamical process of decision making and decision outcomes.

In group buying website, retail stores offer coupons for consuming products/ services in low prices to attract a group of people, even strangers. Every individual interested in such coupons may not evaluate the values and risks solitarily to make the final decisions, they also refer to others' choices, which is formed during a dynamic process, where people may join in (i.e., make a buy decision) or leave (i.e., cancel an order) the group before the deal is done. Accordingly, this study followed Yen and Chang's [53] idea to propose a simplified model to integrate the perspective of collectivism into the traditional view of price, value, and trust and risks. The sections below will elaborate related concepts in more details.

\subsection{Value, Trust, and Risks of Group Buying}

Group-buying is a behavior of joining a group of strangers to strengthen their collective bargaining power via increasing their scale of economy, forcing retail stores to cut short the price of products to enhance their customer values. GROUPON is a combination from the words "GROUP and COUPON," which literally indicates that the operation of business features a combination of characteristics from group auction and coupon. Retail stores announce pleasing prices of their offerings in the website to entice consumers; once the group size reaches a threshold, joining customers will get a coupon for consuming products in brick and mortar stores at another time. Most of the joining retail stores are brick-and-mortar stores, offering a variety of products in very low prices.

For stores that are recently opened, initiating tactics of group buying could be an effective marketing campaign to improve their exposure to potential customers and increase sales rapidly [26]. Yet, some of the existing customers may also be attracted by the eye-catching offers to change their minds to purchase the coupon, since low price attracts repeat buyers more than new customers [33]; even they still go directly to the stores, while consuming in the stores, they may reap less benefits eroded by customers using coupon. To avoid such flaws, retail stores always impose some limitations upon the usage of coupon [20]. However, this policy may also be harmful to the customer value from using coupon.

Except for the negative influence on customer value, group buying may still bring a few troublesome problems to potential customers. Firstly, product quality could be uncertain before its consumption. Price is a signal of product quality [45]; many consumers may perceive an inferior quality since the price is low [20]. In addition, people may find it difficult to trust unfamiliar stores, and may instead perceive a higher degree of uncertainty of outcomes from a decision to buy product from these stores [20]. To summarize, people who get a coupon in the website may face a poorer situation where they get only lesser value and high uncertainty.

\subsection{Perceived Value}

Consumption value, or consumer value, is defined as an "overall assessment of the utility of a product based on the perceptions of what is received and what is given" [54, p.14]. Value can be defined as what you are paying for what you are getting [54]. It is a tradeoff between the sacrifice one paid to get, and the benefits or utility received from the 
consumption of the products. Some authors conceptualized the "get" component as the quality of the product. There is plentiful empirical evidence support the idea that value positively impacts customers' purchase intention [e.g., 11, 44], either directly or indirectly.

Underlying the above definition is the assumption of rational consumer. Customers care very much about the performance of a product's physical attributes, or the benefits received from product consumption [28]; in other words, the product is viewed as a solution to specific problems or needs, and the process of product procurement and consumption is viewed as a task to fulfill some specific objectives [8]. This can explain why people would compare and make a trade-off between the give and the get component to select a product [11].

Yet, some authors argued that a rational view of consumer value may neglect subjective experiences gained from product consumption, like emotional responses, satisfaction of one's interests [28], etc. These authors possessed a viewpoint that value is the composition of every kind of subjective experiences induced during product consumption $[28,54$, p. 13]. Hence, the purpose of product consumption is not task-oriented only, but is also an effort trying to gain and enjoy various hedonic values $[9$, $10]$.

Babin, Darden and Griffin [4] accordingly classified consumer value into two dimensions: utilitarian and hedonic value. Many researchers support this classification and stated that it is appropriate to view value as a dual-nature concept. Since the products sold in the website may not only satisfy people's utilitarian demands, but can also enable people to enjoy new experiences, generating emotions like excitement, curiosity etc., this study offers the following hypothesis:

H1a: Utilitarian value positively impacts purchase intention;

H1b: Hedonic value positively impacts purchase intention.

\subsection{Decisions under Uncertainty and Perceived Risk}

Making decisions under uncertain situations may easily impose loss and risks on decision makers. Previously, risk was defined as the probability of the occurrence of unexpected outcomes after making decisions under uncertain situations [31]; in context of consumption decisions, unexpected outcomes normally means potential monetary loss or physical harms incurred from consuming products purchased. Cox [16] defined the perceived risk as a formula of the two factors: (1) The possibility of the realization of unexpected outcomes perceived before purchase; and (2) The subjective perception of loss incurred upon the decision makers after unexpected outcomes realized. Cunningham [18] named the first factor as uncertainty, and defined it as consumers' subjective judgment of the probability of realizing unexpected outcomes; and he named the second factor as consequence, and defined it as the jeopardy incurred after the happening of some risk events.
Normally, people are unable to be certain beforehand of the accurate probability of an expected outcome [42]. While making uncertain decisions, many strategies could be employed to control expected risks, or reduce expected loss [e.g., 16]. Normally, people will try to collect information to make an informed decision, accurate enough to reduce the uncertainty to a tolerable level $[6,16]$. Yet, if the group-buying customers are unable to know in advance whether their decisions could bring them expected benefits, they may perceive the existence of risks. This study believes that risk is unavoidable in the conduct of group buying. This is because group-buying behavior in nature is uncertain in regards to its results, due to a lack of sufficient information about an unfamiliar retail store in the website to make a well-informed judgment about a product's quality. Due to the information asymmetry between the two parties, stores owners may be more or less opportunistic in their behaviors; once any negative consequences occurred, consumers may have to bear some degree of loss.

The size of the risk be may be partially dependent on: (1) the consumers' attitudes to avoid negative consequences; (2) the consumers' perceptions of the degree of uncertainty (hence, the probability of the happening of negative consequences); and (3) the degree that consumers lay emphasis on the purchase results $[7,16]$. Normally, ordinary people are oreineted toward risk aversion. If s/ he thinks that it is important to avoid negative consequences, or perceives a higher degree of uncertianty, the percpetion of risks will be riased also [7, 16]. It is found that, the higher the perceived risks, the higher the perceived expected loss, inhibiting greatly the consumers' purchase intentions [e.g., 17]. This finding has also been widely supported in articles related with e-commerce [e.g., see 14, $23,35]$ and group buying [13]. Accordingly, this study proposed hypothesis 2 :

$\mathrm{H} 2$ : perceived risk will negatively influence the intention to buy coupon in the website.

\subsection{Trust and Risk}

Trust means that, in situations with potential negative consequences, one party is still willing to rely on the other's commitment with a feeling of relative security [31]. Trusting someone with something reflects the belief in in his/ her ability to fulfill an attitude of caring the commissioned commitment [5]. In other words, the trustee will try his/ her best to follow certain policies, moral code or laws to fulfill his/ her commitment. Trust is an important foundation for building mutual relationship, and constructing and simplifying the cooperation mechanism between an individual and organizations. As indicated in Morgan and Hunt [43], partners of a relational transaction can develop and maintain a successful exchange relation through the encouragement of mutual trust. Hence, trust can be viewed as a psychological state of agreeing with someone else's behavioral intention under the basis of positive expectation [48]. To attract customers, Kim et al. 
[33] found that perceived trust exerted a stronger effect than low price does, especially for potential customers; while low price is more effective in attracting repeat buyers.

Based on the definition of trust, one can infer that a better trust will lead to a lesser degree of perceived risk. This assertion has wide supports in the literature [e.g., 25, 26]. Though an opposite argument is proposed by some authors [e.g., 15], the mathematical model formulating the relationship between trust and risk proposed by Jøsang and Lo Presti [31] is convincing and can be applicable to a variety of generic and wide contexts of business transactions. Accordingly, hypothesis 3 is proposed:

H3: Trust negatively influences risk.

\subsection{Price and Price Consciousness}

Price is the monetary sacrifice paid to get the product or service. Price is an informational cue of product quality [45]; many researchers deployed the price-quality relationship to explain and predict consumers' product choices [e.g., 47]. That is to say, price is an expression of product quality and value; therefore, become an important external cue for product selection.

Due to the influences from individual or situational factors, consumers may perceive a same objective price as either high or low. Lichtenstein, Ridgway \& Netemeyer [37, p.234] further argued that price is a complex stimulus perceived more broadly by consumers than strictly its sacrifice role as an outlay for product or service. Seven different beliefs about price had been summarized in their article:

1. value consciousness: a concern with the ratio of the quality received to price paid;

2. price consciousness: the degree to which the consumer focuses on paying low prices;

3. coupon proneness: price reduction in coupon form produce an increase in consumer responses beyond that which would result from an equivalent lower non-coupon price [38];

4. sale proneness: increased sensitivity to price is induced by the price discount in sale form, which increased responses stronger than that from a reference price [38];

5. price mavenism: a desire to be informed about the prices to transmit such information to others [25];

6. price-quality schema: price is an inference of product quality;

7. prestige sensitivity: a perception due to inferences about what price signal to others about the buyers, like prominence or status.

Not every price belief plays a role in group buying context. According to the definition of uncertainty and risk, a low price may intuitively implicate a lesser loss from the occurring of negative outcomes. Yet, consumers with different price beliefs may generate a different reaction to the role of low price in the evaluation of risk. The latter two types of consumers may prefer higher price, and care less about how much the loss would be. Consumer as market maven is not the focus of the present study, since this perception has nothing to do with the evaluation of risk.

The responses from consumers with sale proneness may be raised by price reduction to a degree enough to care less about the potential loss. Furthermore, the group buying coupon is dissimilar with traditional coupon in the sense that it is not a certificate for price reduction while buying a product, but more like a pre-paid card to consume a specific product in the future. It may not produce a coupon effect on consumers with coupon proneness to go shopping in the website. Finally, for value consciousness consumers, an unfamiliar retail store name may imply an uncertain quality; they may care more about the ratio of value, rather than about how much the loss would be while buying in the website. Accordingly, this study proposed the following hypothesis:

$\mathrm{H} 4$ : price consciousness is negatively related with risk.

\subsection{Conformity Intention}

The amount of people participating in group buying may also be an external cue of product quality, just like people evaluate and purchase books according to the sales ranking. Stern and Stafford [2006] found that increasing consumer participating was positively correlated with the attractiveness of the goods being auctioned to observing consumers. In other words, people could follow others' collective decision to decide their own behaviors. This type of behavior is named as herding or conformity behavior.

Conformity behavior is defined as: the adoption of behaviors similar to that taken by members of a group to gain the recognition from that group [51]. SIDE model (Social Identity Model of Deindividuation Effects) posits that a lack of individuating cues in computer-mediated communication (CMC) environment makes group memberships salient to induce the adoptions of group norms, hence, making similar initiatives become prevailing among these members. The SIDE effects is claimed to be much stronger in CMC than in face to face environment [32].

Previously, group size was found to be an important antecedent of conformity intention [3, 34]. Nevertheless, Asch [3] found that, while dealing with a controversial issue, whether or not a consensus of the peers' opinions was derived may also interfere in the creation of conformity intention; the existence of opponents may help members with different opinions feel less pressure to conform others' decisions.

Conformity behavior is also viewed as the outcome of social influence process. Two basic human needs triggered this social influence process: (1) a desire to be accepted, to be like, to have a sense of belonging; (2) a desire to be accurate [6]. A typology was hence proposed to classify the social influence into normative and informative processes. The latter occurs normally in situations of making decisions under uncertainty, causing the decision makers difficult to judge accurately and choose correctly the best alternative, putting him/ her into a dilemma. 
Researchers noted how judgment difficulty causes conformity behavior very early [e.g., 21]. Baron et al. [6] further noted that: if judgment outcomes are important, people are more likely to undertake social comparison to search for accurate and informed answer. From such viewpoint, conformity behavior can be said to be triggered by information asymmetry between one and the referred group of people; in other words, one may perceive an inconsistence between information owned by him/ herself and that owned by a group of people reaching a consensus in choosing an answer; therefore may give up private information, and take the collective behavior chosen by a group of people as an external information for decision making.

Due to anonymity, researchers argued that conformity behavior in virtual group is less likely activated by normative social influence. Instead, it is more likely being initiated by informative social influence. Then, the consensus of a group in selecting an answer will be viewed as a more accurate and well informed collective intelligence, which in turn is used an information filter to solicit one's private information, and to turn one to follow the group behavior [40]. Similar with this assertion, Hanson and Putler [27] found that the number of downloads is viewed as an indicator of software quality; the higher the number, the stronger the attractiveness of the software to other potential users. Dholakia and Soltysinski [19] also found consumers would choose to bid a hottest auctioned product, rather than other product with similar, or even better quality. These findings showed that consumers may at some time give up their private information, but follow a group behavior.

Since group decision is perceived as more accurate and better informed, conformity behavior may reduce the followers' subjective evaluation of the probability of occurring negative outcomes, hence leading to a lower perception of risk. Yet, not every person has the same degree of conformity intention; empirical evidence showed that consumers with risk aversion are more likely adopting conformity behavior [50]. Risk averted consumers may be more inclined to bear less risk, hence be more conservative, and favor more to distribute or reduce risk. Relatively, they are more apt to conduct conformity behavior. Since consumers with or without risk aversion may have different level of conformity intention, this study proposed the following hypothesis:

H5: The higher the conformity intention, the lower the perception of risk.

Based on the literature reviewed, a theoretical model was derived (figure 1) to explain why people would choose to purchase in the website, rather than go directly to the brick-mortar stores. A consumer's decision to purchase the coupon is viewed as a trade-off between the value gained and the risk being exposed. Furthermore, except the perception of trust, this study also hypothesized that consumers with price consciousness and conformity intention will perceive a lower degree of risks.

\section{Research Method}

This study conducted a questionnaire survey to collect data for hypotheses testing. In order to ensure the content and face validity, all questionnaire items were adapted from existing questionnaire with good reliability, and validity to fit into the research context. Table 1 summarizes the operational definition of each variable, the sources of measurement scale, and the number of original items. This study invited three experts and four representative samples to participate in the pretest of the questionnaire. Some of the phrases and the order of appearance of these items were adapted according to their opinions given in three sessions of discussions.

The unit of analysis is the members of the group buying website with experiences of purchasing coupons of product or services. Internet questionnaire was used for data collection and purposive sampling was used to increase the degree of generalization of the sample. Volunteers were invited to participate in this survey via posting hyperlinks in bulletin board, and sending e-mails and MSN inquiries to students, friends, and relatives of the authors. The data collection lasted for two weeks, and finally 164 valid questionnaires were retrieved.

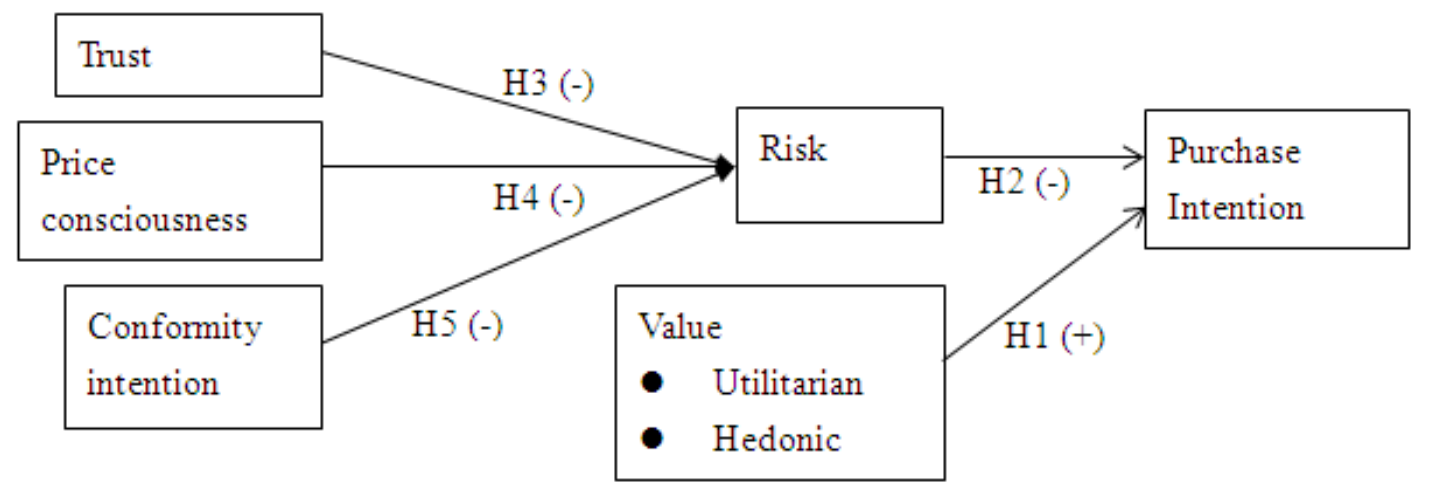

Figure 1. Research model of this study 
Table 1. Variable definition and operationalization

\begin{tabular}{cccc}
\hline variable & definition & source & items \\
\hline PI & The probability of purchasing product in group buying website in & the next 6 months & 4 \\
PT & The perceived degree of trust in the group buying website & Kim et al. [33] & 5 \\
PC & The degree of inclination of buying product in low price & Kukar-Kinney[36] & 5 \\
HV & $\begin{array}{c}\text { The perceived enjoyment and emotional responses derived from } \\
\text { purchasing and consuming product in the website }\end{array}$ & Babin et al. [4] & 12 \\
UV & $\begin{array}{c}\text { The degree of perceived convenience of and fulfillment of the } \\
\text { objectives of the purchasing task conducted in the website. }\end{array}$ & Babin et al. [4] & 6 \\
PR & $\begin{array}{c}\text { The perceived total risk of purchasing product, measured in terms } \\
\text { of financial risks, performance risks, and privacy risks. }\end{array}$ & Kuhlmeier \& Knight [35] & 4 \\
CI & $\begin{array}{c}\text { The probability of following other people's decisions to purchase } \\
\text { product in the website. }\end{array}$ & Kim \& Park [32] & 4 \\
\hline
\end{tabular}

Abbreviation: PI- purchase intention; PT- perceived trust; PC- price consciousness; HV- hedonic value; UV- utilitarian value; PR- perceived risk; CIconformity intention

\section{Data Analysis}

\subsection{Samples}

The sample of this study is mainly composed of young female with relatively low incomes, which is similar to the profiles reported in some recent surveys conducted by Nownews, an Internet news platform, and the Market Intelligence \& Consulting Institute [41], a not-for-profit organization founded by government to promote Taiwan's information industry, and Yen and Chang [53].

MIC [41] found that most of the online group-buying buyers were female with ages ranging from 20 to 29 . Nownews ${ }^{3}$ concluded that the consumers of the group buying website are mainly young ladies with ages ranging from 26-35, and monthly incomes less than NT\$35,000 (about US\$ 1,100). In addition, Yen and Chang [53] found that their samples were primarily female $(95.9 \%)$ with ages ranging from $25-35$ (58.3\%).

Of the 164 respondents in this study, $98(59.8 \%)$ were female, $99(60.3 \%)$ were between 23 and 30 years of age, and the ages of 141 samples $(85.9 \%)$ were ranging from 19-30. Furthermore, near half of the samples $(48.7 \%)$ were student, and $137(83.4 \%)$ of them have monthly incomes less than NT\$ 40,000. Finally, 95 of the samples $(57.9 \%)$ have more than 5 times experiences of purchasing in the websites, which is consistent with Yen and Chang [53] in that most respondents in their study were frequent buyers of group buying.

The similarity among different surveys indicates that the sample in this study can be seen as a representative sample of the larger population of group-buying users, who possessed sufficient experience to answer the questions posed by the questionnaire used in this study. Table 2 lists the demographic characteristics of the respondents.

Data will be analyzed by Partial Least Square (PLS), and SmartPLS 2.0 will be employed as the primary tool for data

3 http://www.nownews.com/2011/08/01/91-2732104.htm, accessed in 10 June, 2012 analysis ${ }^{4}$. The R-square for the dependent variable and the size, along with the t-statistics and significance level of the structural path coefficients were chosen as criteria of quality evaluation [52]. PLS can be utilized to confirm theory as well as explain very complex relationship among latent variables [13]. More importantly, it is most suitable for small sample size situation to test a set of hypotheses. The analysis using standard PLS procedure is composed of analyzing the data in two stages, and the results will be presented below. First, the measurement model is assessed for validity and reliability; then, the structural model is evaluated to test the hypotheses.

Table 2. Demographic Information of Respondents

\begin{tabular}{|c|c|c|c|}
\hline Measures & items & Frequency & Percentage \\
\hline \multirow{2}{*}{ Gender } & Male & 66 & 40.2 \\
\hline & Female & 98 & 59.8 \\
\hline \multirow{5}{*}{ Age } & $16-18$ & 1 & 0.6 \\
\hline & $19-22$ & 42 & 25.6 \\
\hline & $23-25$ & 62 & 37.8 \\
\hline & $26-30$ & 37 & 22.5 \\
\hline & $31-40$ & 22 & 13.5 \\
\hline \multirow{4}{*}{ Occupation } & Student & 80 & 48.7 \\
\hline & Employment & 77 & 46.9 \\
\hline & NEET $^{*}$ & 4 & 2.5 \\
\hline & Others & 3 & 1.9 \\
\hline \multirow{2}{*}{$\begin{array}{l}\text { Shopping } \\
\text { Experience }\end{array}$} & $<=5$ & 69 & 42.1 \\
\hline & $>5$ & 95 & 57.9 \\
\hline \multirow{5}{*}{$\begin{array}{l}\text { Monthly } \\
\text { income }\end{array}$} & $<=\mathrm{NT} \$ 20,000$ & 86 & 52.4 \\
\hline & $20,001-40,000$ & 51 & 31.1 \\
\hline & $40,001-60,000$ & 24 & 14.7 \\
\hline & $60,001-80,000$ & 1 & 0.6 \\
\hline & $>80,001$ & 2 & 1.2 \\
\hline
\end{tabular}

* Non employment, education, or training 2005, http://www.smartpls.de. 


\subsection{Measurement Model}

Exploratory factor analysis (EFA) and Cronbach's $\alpha$ were used to evaluate and improve the reliability and validity of our measurement model. Since the KMO value is 0.836 , and the Bartlett's test of Sphericity is significant, a principal components analysis with orthogonal rotation by varimax method was conducted. Nine factors with eigenvalues value larger than one were extracted. Table 3 summarized the results of EFA.
According to the results of EFA, some items, including PC4, PR3, PR4, and HV8, were dropped, because they either have a factor loading less than 0.5 , and/ or are loaded into incorrect factors. For the same reasons, all the items of utilitarian value are deleted. Hence, the hypothesis 2-1 can't be tested. The remaining variables' Cronbach's $\alpha$ values are all greater than 0.7 , with a highest value of 0.918 (PIpurchase intention) and a lowest value of 0.728 (PC-price consciousness).

Table 3. The results of EFA

\begin{tabular}{|c|c|c|c|c|c|c|c|c|c|}
\hline \multicolumn{10}{|c|}{ Factor } \\
\hline & 1 & 2 & 3 & 4 & 5 & 6 & 7 & 8 & 9 \\
\hline PC1 & & & & & & .765 & & & \\
\hline PC2 & & & & & & .765 & & & \\
\hline PC3 & & & & & & .527 & & & \\
\hline$P C 4^{a}$ & & & & & & -.477 & & & \\
\hline PT1 & .748 & & & & & & & & \\
\hline PT2 & .806 & & & & & & & & \\
\hline РT3 & .703 & & & & & & & & \\
\hline PT4 & .764 & & & & & & & & \\
\hline PT5 & .678 & & & & & & & & \\
\hline PR1 & & & & & .804 & & & & \\
\hline PR2 & & & & & .726 & & & & \\
\hline $\mathbf{P R 3}^{\mathrm{b}}$ & & & & & & & & & .556 \\
\hline \multicolumn{10}{|l|}{$\mathrm{PR}^{\mathrm{a}}$} \\
\hline HV1 & & .665 & & & & & & & \\
\hline HV2 & & .625 & & & & & & & \\
\hline HV3 & & .606 & & & & & & & \\
\hline HV4 & & .743 & & & & & & & \\
\hline HV5 & & .591 & & & & & & & \\
\hline HV6 & & & & & & & & .664 & \\
\hline $\mathrm{HV}^{\mathrm{a}}$ & & & & & & & .426 & & \\
\hline HV8 & & & & & & & & .503 & \\
\hline $\mathbf{U V 1}{ }^{\mathbf{a}, \mathbf{b}}$ & & & & & & & .436 & & \\
\hline $\mathbf{U V} 2^{\mathbf{a}, \mathbf{b}}$ & & & & & .440 & & & & \\
\hline $\mathbf{U V 3}^{\mathbf{b}}$ & & & & & & & .553 & & \\
\hline $\mathbf{U V 4}^{\mathrm{b}}$ & .502 & & & & & & & & \\
\hline $\mathbf{U V 5}^{\mathbf{a}, \mathbf{b}}$ & .454 & & & & & & & & \\
\hline \multicolumn{10}{|l|}{$\mathbf{U V 6}^{\mathbf{a}}$} \\
\hline PI1 & & .850 & & & & & & & \\
\hline PI2 & & .777 & & & & & & & \\
\hline PI3 & & .770 & & & & & & & \\
\hline CI1 & & & & .687 & & & & & \\
\hline $\mathrm{CI} 2$ & & & & .603 & & & & & \\
\hline CI3 & & & & .777 & & & & & \\
\hline CI4 & & & & .825 & & & & & \\
\hline
\end{tabular}

Note: Suppress absolute values $<0.4$.

Abbreviation: PI- purchase intention; PT- perceived trust; PC- price consciousness; HV- hedonic value; UV- utilitarian value; PR- perceived risk; CI- conformity intention

a: Loading $<0.5$

b: Loaded into incorrect factor 
The convergent validity was evaluated by average variance extracted (AVE), and composite reliability (CR). The results, shown in table 4 indicate that the AVE of the variables are all larger than 0.5 ; the composite reliability of the variables are all greater than 0.7 , indicating a satisfactory level of convergent validity. Finally, all the square roots of AVEs were larger than the correlations between variables, providing evidence of discriminate validity for the measurements (table 5).

Table 4. Summary of the Results of Convergent Validity Analysis

\begin{tabular}{|c|c|c|c|}
\hline Variable & AVE & CR & Cronbach's alpha \\
\hline CI & 0.6785 & 0.8940 & 0.8418 \\
\hline HV & 0.5422 & 0.8732 & 0.8289 \\
\hline PC & 0.6406 & 0.8405 & 0.7282 \\
\hline PI & 0.8600 & 0.9485 & 0.9186 \\
\hline PR & 0.8220 & 0.9023 & 0.7856 \\
\hline PT & 0.6655 & 0.9086 & 0.8757 \\
\hline
\end{tabular}

Abbreviation: PI- purchase intention; PT- perceived trust; PC- price consciousness; HV- hedonic value; UV- utilitarian value; PR- perceived risk; CI- conformity intention

Table 5. Summary of the Results of Discriminant Validity Analysis

\begin{tabular}{|c|c|c|c|c|c|c|}
\hline & CI & HV & PC & PI & PR & PT \\
\hline CI & 0.8237 & & & & & \\
\hline HV & 0.3947 & 0.7363 & & & & \\
\hline PC & 0.1649 & 0.1927 & 0.8004 & & & \\
\hline PI & 0.3905 & 0.4897 & 0.1570 & 0.9274 & & \\
\hline PR & 0.0037 & -0.1447 & -0.0462 & -0.2918 & 0.9066 & \\
\hline PT & 0.2705 & 0.3913 & 0.0602 & 0.3575 & -0.2792 & 0.8158 \\
\hline
\end{tabular}

*Diagonal elements: the square root of the average variance extracted (AVE).

Abbreviation: PI- purchase intention; PT- perceived trust; PC- price consciousness; HV- hedonic value; UV- utilitarian value; PR- perceived risk; CI- conformity intention

Table 6. Results of hypotheses testing

\begin{tabular}{|c|c|c|c|c|}
\hline hypothesis & path & Coefficient (t) & R square & support \\
\hline H1b & HV $\rightarrow$ PI & $0.459\left(8.547^{* * *}\right)$ & \multirow{2}{*}{0.291} & Yes \\
\cline { 1 - 3 } H2 & PR $\rightarrow$ PI & $-0.222\left(3.99^{* * *}\right)$ & & Yes \\
\hline H3 & PT $\rightarrow$ PR & $-0.299\left(5.503^{* * *}\right)$ & \multirow{2}{*}{0.163} & Yes \\
\cline { 1 - 3 } H4 & PC $\rightarrow$ PR & $-0.0590(0.540)$ & & No \\
\cline { 1 - 2 } & H5 $\rightarrow$ PR & $0.094(0.797)$ & &
\end{tabular}

Abbreviation: PI- purchase intention; PT- perceived trust; PC- price consciousness; HV- hedonic value; PR- perceived risk; CI- conformity intention

\subsection{Hypotheses Testing}

The results, illustrated in table 6 , show that the variance of PI explained is 0.291 , and the variance of PR explained is only 0.103 . The main effects of PR $(\beta=-.222, t=3.99, p$ $<.05)$ and HV $(\beta=.459, \mathrm{t}=8.547, \mathrm{p}<.05)$ on PI are as expected as $\mathrm{H} 1$ and $\mathrm{H} 2 \mathrm{~b}$ and statistically significant, respectively. Hence, the results tend to support these two hypotheses. The effects of PT $(\beta=-.299, \mathrm{t}=5.503, \mathrm{p}<.05)$ is also as expected as $\mathrm{H} 3$ and statistically significant. Hence, the results tend to support this hypothesis. Unfortunately, the results reject $\mathrm{H} 4$, and $\mathrm{H} 5$ since both path coefficients are far from statistically significant.

\section{Conclusions and Discussions}

Though group-buying is gradually becoming popular among Internet users, some of the players were being forced to leave this business recently. Standing on the assumptions that group buying offers an opportunity for consuming experiential products with potentially high risks, whether or not to purchase coupon in the website, instead going to the stores directly, is hypothesized as a trade-off between the value and risks perceived. A theoretical model was built and tested, hoping that the findings can explain why consumers decide to purchase products via this new platform.

The results indicate that the purchasing intention is inhibited by perceived risk ( $\mathrm{H} 2)$, and at the same time, is improved by perceived hedonic values ( $\mathrm{H} 1 \mathrm{~b})$. This finding is consistent with previous literature [e.g., see 12, 17]. Yet, the effects from hedonic value $(\beta=.459)$ is far greater than that from perceived risks ( $\beta=-.222)$, showing that consumers are driving to shop here mainly because of pursuing enjoyment and subjective experiences from the consumption behavior.

Some managerial implications may be provided from these findings. Firstly, group buying website can try to enhance purchase intention by tactics of enhancing customers' degree of trust such as ensure product quality, response quickly to dissatisfied customers etc. In particular, they can provide a more generous money back guarantees. Jeng et al. [30] found that when the perceived price of a product is low, a more generous money back guarantees policy will effectively increase the believability of such policy, no matter the stores is well known or infamous to ordinary customers. The more the customers believe that they will get money back when the deal is problematic, the more likely they will perceive a lower degree of risk. Secondly, group buying websites should also try to improve the perceived hedonic value to produce much greater effects on attracting customers. For example, they can surprise their customers by creating uncertainty associated with a positive event, like giving gifts or offering preferential treatments during the purchasing process. According to Lee and Qiu [37], such type of uncertainty is preferable to ordinary consumers, since people can experience greater, longer lasting positive feelings and pleasure while facing such uncertainty.

The perceived trust, as expected and consistent with previous literature [e.g., 25, 26], negatively influences perceived risks (H3). Nevertheless, it is worthy to note that the variance of risk explained by trust and other variables is only about 16 percent, indicating that there must be still some important antecedents of risk missing from the theoretical model. This peculiar finding may be due to the 
unique nature of group buying. Since the price is low, the expected sacrifice from an incorrect buying decision may also not be so significant. In addition, their actions are back-up by a group of strangers making the same decisions; hence any individual among this group could have more confidences on their decisions than making decision individually [53]. Hence, consumers can pursue hedonic value without too much hesitation and consideration about the potential risks. Therefore, trust, though is relevant, has relatively less influences on their perceptions of risks.

The same rationale may also be used to explain why our guesses that conformity intention may decrease the levels of risks are not true (H5 is rejected). Given that the sacrifices may be trivial enough or affordable to any customer, the act of conforming to the collective intelligence to avoid high risk may be meaningless. Yet, this finding is inconsistent with Yen and Chang's [53] finding that conformity intention positively impacts the attitude toward joining group auction. Interestingly, another explanation for the rejection of $\mathrm{H} 5$ can also be drawn from Yen and Chang's [53, p. 112] arguments. These two authors stated that a group of members may share a belief in their conjoint ability to attain a shared goal. This concept is referred to as collective efficacy, which is most effective in group-level settings. Since the goal of group buying is to increase the group size to exceed the threshold to activate the stores offerings, consumers believe that buying as a group will help them achieve desired outcomes may fear less about the potential risks. The reason why a same construct leads to different findings may have something to do with the different research contexts of these two studies (group purchasing without initiator vs. group auction initiated by a group leader). Researchers are encouraged to further inquire this issue in future studies.

The influences of price consciousness on risks were also found insignificant ( $\mathrm{H} 4$ is rejected), though, as was expected, it impacts risk negatively $(\beta=-0.059)$. This unexpected finding may be attributed to the dual natures of the price. While lower price may produce a perception of fewer losses from a bad decision, it also generates a sense of inferior quality beforehand. Hence, the reduction of perceived risks from expected fewer losses may be offset by the increase of risk from worse quality. Perhaps a future study may try to decompose the above two effects and reveal their true influences.

Finally, the measure of utilitarian value was deleted, which disable the authors for testing the relevant hypothesis (H1a is not tested). Perhaps the measure of this variable, adapted from one used in context of brick-and-mortar stores, is inappropriate for this study. For example, this measure asked the informants to evaluate the speed of completing a purchase. Yet, how fast can a decision be made depends not only one's decision behavior, but also others' actions. It also asked the samples to evaluate the overall satisfaction to the purchasing task. Again, the purchasing task itself involves a dynamic process whose progress depends largely on the dynamism of the group involved, where people may come in into or leave the group dynamically at any time. Also, the purchasing task can only be finished after the consumption of product. Perhaps the nature and characteristics of the utilitarian value in both contexts are far different enough to invalidate the suitability of the current measure. Researchers are encouraged to develop a more suitable measure for this variable and re-test its explanatory power in the future studies.

As a final point, some limitations of this study should be mentioned. To begin with, purposive sampling was deployed in data collection since the nature of the population (those who had purchased coupon in the website) is unknown. Online survey invitations were distributed to invite volunteers to participate in the survey. Hence, problem of self-selection may more or less exist. The small number of samples also raised a concern of insufficient generalizability. Luckily, existing surveys of group buying customers were being referenced as a sampling frame guiding data collection, and the demographic of the samples in this study are similar with those reported in previous study or surveys. Finally, this study may suffer from an unsatisfactory validity problem since the measure of utilitarian value was dropped out. Future studies should try to improve the measure of this variable, and conduct replication researches to further validate the research model.

\section{REFERENCES}

[1] Ajzen I. The theory of planned behavior. Org Behav Hum Decis Process 1991; 50: 179-211.

[2] Albayrak T, Aksoy A, Caber M. The effect of environmental concern and skepticism on green purchase behaviour. Mark Intelligence Planning 2013; 31(1): 27-39.

[3] Asch SE. (1956). Studies of independence and conformity I: A minority of one against a unanimous majority. Psychol Monographs 1956; 70(9).

[4] Babin BJ, Darden WR, Griffin M. (1994). Work and/or fun: Measuring hedonic and utilitarian shopping value. J Consumer Res 1994; 20(4): 644-56.

[5] Baier A. (1985). Trust and antitrust. Ethics 1985; 96: 231-60.

[6] Baron RS, Vandello JA, Brunsman B. (1996). The forgotten variable in conformity research: impact of task importance on social influence. J Personality Soc Psychol 1996; 71(5): 915-27.

[7] Bauer RA. (1960). Consumer behavior as risk taking. Dynamic Marketing in the Changing World, in Hancock RS, ed. Chicago: American Marketing Association 1960; 389.

[8] Bettman JR. An Information Processing Theory of Consumer Choice, Mass: Addison Wesley 1979.

[9] Bloch PH, Bruce GD. Product involvement as leisure behavior. in Kinnear TC, Arbor A eds. Advances in Consumer Research, Vol. 11, MI: Association for Consumer Research 1985; 197-202. 
[10] Bloch PH, Richins ML. (1983). Shopping without purchase: An investigation of consumer browsing behavior. in Bagozzi RP, Tybout AM, Arbor A eds. Advances in Consumer Research 1983, Vol. 10, MI: Association for Consumer Research, 389-93.

[11] Chen YC, Shang RA, Lin AK. The intention to download music files in a P2P environment: Consumption value, fashion, and ethical decision perspectives. Electronic Commerce Res Applications 2008: 7(4): 431-42.

[12] Cheng SY, Tsai MT, Cheng NC, Chen, KS. Predicting intention to purchase on group buying website in Taiwan. Online Inf review 2012; 36(5): 698-712.

[13] Chin W, Marcolin B. Newsted P. (1996). A partial least squares latent variable modeling approach for measuring interaction effects: results from a Monte Carlo simulation study and voice mail emotion/adoption study. In Degross JI, Javenpaa S, Srinivasan A eds. The Proceedings of $17^{\text {th }}$ International Conference on Information Systems 1995; 21-41.

[14] Choi J, Geistfeld LV. A cross-cultural investigation of consumer e-shopping adoption. J Econ Psychol 2004: 821-38.

[15] Corbit BJ, Thanasankit T, Yi H. Trust and e-commerce: A study of consumer perceptions. Electronic Commerce Res Applications 2004; 2: 203-15.

[16] Cox DF. (1967). Risk Taking and Information Handling in Consumer Behavior 1967. Boston, MA: Harvard University Press.

[17] Crespo AH. Bosque IR. The influence of the commercial features of the Internet on the adoption of e-commerce by consumers. Electronic Commerce Res Application 2010; 562-75.

[18] Cunningham SM. The major dimension of perceived risk, in Cox DF ed. Risk Taking and Information Handling in Consumer Behavior 1967; 82-108. Boston: Harvard University Press.

[19] Dholakia UM, Soltysinski K. (2001). Coveted or overlooked? The psychology of bidding for comparable listings in digital auctions. Mark Letters 2001; 12(3): 225-37.

[20] Dholakia UM, Tsabar G. (2011). A Startup's Experience with Running a Groupon Promotion [Working paper]. 2011. Mimeo, Rice University.

[21] Deutsch M, Gerard HB. A study of normative and informational social influences upon individual judgment. J Abnormal Soc Psychol 1955; 51: 629-63.

[22] Edelman B, Jaffe S, Kominers S.D. To Groupon or not to Groupon: The profitability of deep discount. Harvard Business School 2011, Working Paper 11-063.

[23] Featherman MS, Pavlou PA. (2003). Predicting e-services Adoption: A perceived risk facets perspective. Int J Hum Comput Stud 2003; 59: 451-74.

[24] Feick $L F$, Price LL, Higie RA. Information sensitive consumers and market information. J Consum Affairs 1987; 21(2): 328-41.

[25] Gefen D. Nurturing clients' trust to encourage engagement success during the customization of ERP systems. Omega
2002; 30(4): 287-99.

[26] Gefen D, Karahanna E, Straub DW. (2003). Trust and TAM in online shopping: An integrated model. MIS Quarterly 2003; 27(1): 51-90.

[27] Hanson WA, Putler DS. Hits and misses: Herd behavior and online product popularity. Marketing Letter 1996; 7(4): 297-305.

[28] Holbrook MB, Hirschman EC. The experiential aspects of consumption: Consumer fantasies, feelings, and fun. J Consum Res 1982; 9: 132-40.

[29] Hsu MH, Yen CH, Chiu CM, Chang CM. (2006) A longitudinal investigation of continued online shopping behavior: An extension of the theory of planned behavior. Int J Hum Comput Stud 2006; 64(9): 889-904.

[30] Jeng SP, Huang LS, Chou, YJ, Teng, CI. Do consumers perceive money-back guarantees as believable? The effects of money-back guarantee generosity, store familiarity, and perceived price. Service Sci 2014; 6(3): 179-89,

[31] Jøsang A, Lo Presti S. (2004). Analyzing the relationship between risk and trust. in Jensen CD ed. iTrust 2004; LNCS 2995, 135-45.

[32] Kim JH, Park HS. The effect of uniform virtual appearance on conformity intention: Social identity model of deindividuation effects and optimal distinctiveness theory. Comput Human Behav 2011; 27: 1223-30.

[33] Kim HW, Xu Y, Gupta S. Which is more important in Internet shopping, perceived price or trust? Electronic Commerce Res Applications 2012; 11:241-52.

[34] Kishida M. (1956). A study of the effects of group norm upon the change of opinions. Jap. J. Psychol 1956; 27: 172-73.

[35] Kuhlmeier D, Knight G. Antecedents to internet-based purchasing: A multinational study. Int Mark Review 2005; 22(4): 460-73.

[36] Kukar-Kinney M, Ridgway NM, Monroe KB. The role of price in the behavior and purchase decisions of compulsive buyers. J Retailing 2012; 88(1): 63-71.

[37] Lee YH, Qiu C. (2009). When uncertainty brings pleasure: The role of prospect imageability and mental imagery. J Consum Res 2009; 36.

[38] Lichtenstein DR, Netemeyer RG, Burton S. Distinguishing coupon proneness from value consciousness: An acquisition-transaction utility theory perspective. J Mark 1990; 54-67.

[39] Lichtenstein DR, Ridgway NM, Netemeyer RG. Price perceptions and consumer shopping behavior: A field study, J Mark Res; 1993; 30: 234-45.

[40] Lin ZP. (2002). The Effect of Conformity Based Filtering on Information Load [Master Thesis]. Tainan, Taiwan: National Chung-Cheng University; 2002. Chinese.

[41] MIC (Market-Intelligence-Consulting-Institute). The Customer Behavior of Group-Buying Auctions Sites in 2010. Institute for Information Industry. 2013.

[42] Mitchell VW. Consumer perceived risk: Conceptualizations and models. Eur J Mark 1999; 33 (1/2): 163-95. 
[43] Morgan RM, Hunt SD. (1994). The commitment-trust theory of relationship marketing. J Mark 1993; 58 (July): 20-38.

[44] Monroe KB. Pricing: Making Profitable Decisions. New York: McGraw Hill. 1990.

[45] Olson JC. Price as an informational cue: Effects on product evaluations. in Woodside AG, Sheth JN, Bennett, PD eds. Consumer and Industrial Buying Behavior, New York: North Holland, 1977: 267-86.

[46] Pavlou PA, Gefen D. Building effective online marketplaces with institution-based trust. Inf Systems Res 2004; 15(1): 37-59.

[47] Rao AR, Monroe KB. (1989). The Effect of price, brand name, and store name on buyers' perceptions of product quality: An integrative review. J Mark Res 1989; 26 (August): 351-57.

[48] Singh J, Sirdeshmukh D. Agency and trust mechanisms in consumer satisfaction and loyalty judgments. J Academy Mark Sci 2000; 28(1): 150-167.
[49] Stern BB, Stafford MR. Individual and social determinants of winning bids in online auctions. J Consum Beh 2006; 5: $34-55$

[50] Wang SY. (2003). Individual Factors and the Analysis of Decision Process of Herding Behavior [Master Thesis]. Hualian, Taiwan: National Dong Hwa University, 2004. Chinese.

[51] Wilkie M. Consumer Behavior. 3rd ed. New York: John Wiley and Sons Inc., 1994.

[52] Wold, H. Systems analysis by partial least squares. Measuring the unmeasurable 1985; 221-51.

[53] Yen CH, Chang, CM. Unity is stregnth: Understanding users' group buying behavior in Taiwan from a collectivism perspective. J Electronic Commerce Res 2015; 16(2): 109-22.

[54] Zeithaml VA. (1988). Consumer perceptions of price, quality, and value: A means-end model and synthesis of evidence. J Mark 1988; 52 (July): 2-22. 